\title{
Purpura is Not Always Caused by the Anticoagulant
}

\author{
Catarina Faria, Fernando Henriques, José Leite, Célio Fernandes
}

Department of Internal Medicine 2, Hospital de Leiria, Leiria, Portugal

Received: $16 / 11 / 2016$

Accepted: $16 / 12 / 2016$

Published: 01/02/2017

How to cite this article: Faria C, Henriques F, Leite J, Fernandes C. Purpura is not always caused by the anticoagulant. EJCRIM 2017;4:

doi:10.12890/2017_000536

Conflicts of Interests: The Authors declare that there are no competing interests.

This article is licensed under a Commons Attribution Non-Commercial 4.0 License

\section{ABSTRACT}

Pigmented purpuric dermatosis is a chronic benign skin disorder of unknown aetiology. Although there are several other potential cofactors, drugs are the most frequent cause. This paper describes the case of a 71-year-old woman who was admitted in the emergency department with skin lesions on the lower extremities, characteristics of Schamberg's disease. After a medical study and treatment, it was concluded that the lesions were caused by amlodipine administration. To the authors' knowledge, only one previous case describing an association between this disease and amlodipine administration has been reported in the medical literature.

\section{LEARNING POINTS}

- Schamberg's disease is the most common form of pigmented purpuric dermatosis.

- The condition can be caused by amlodipine administration.

- This is a rare but benign skin disorder.

\section{KEYWORDS}

Schamberg's disease; amlodipine

\section{INTRODUCTION}

Pigmented purpuric dermatoses (PPD) are chronic, benign and relapsing skin disorders of unknown aetiology ${ }^{[1]}$. They are characterized by the presence of petechiae, purpura and hyperpigmentation, that can be either asymptomatic or pruritic ${ }^{[1]}$. The lesions are mostly seen on the lower limbs but may occur anywhere on the body. There are five different types of PPD with the most common being Schamberg's disease (SD), which is also known as progressive pigmentary purpura ${ }^{[2,3]}$.

\section{CASE REPORT}

A 71-year-old woman was admitted in the emergency department with skin lesions on the lower extremities. She had petechial asymptomatic lesions which had evolved over 5 days, her medical history included hypertension, atrial fibrillation and dyslipidaemia, and she was chronically medicated with nebivolol $5 \mathrm{mg}$ once a day, simvastatin $20 \mathrm{mg}$ once a day, olmesartan 20 mg once a day, dabigatran 110 $\mathrm{mg}$ twice a day, amlodipine $5 \mathrm{mg}$ once a day and omeprazole $20 \mathrm{mg}$ once a day. She had no history of recent medication adjustment. There were no significant changes in complete blood count, erythrocyte sedimentation rate (ESR) or prothrombin, and there was only a slight increase in the partial prothrombin time $(50.8 \mathrm{sec})$ due to the ingestion of dabigatran. She was referred to the outpatient clinic of the internal medicine department where she was instructed to stop dabigatran and omeprazole and to start taking prednisolone 20 mg once a day and rivaroxaban $20 \mathrm{mg}$ once a day. 
The patient was observed 1 month later by which time the skin lesions had progressively worsened (Fig. 1). The results of blood examinations including a full blood count, peripheral blood smear, coagulation screen and ANA, did not show any changes but the partial prothrombin time $(32.1 \mathrm{sec}$ ) had normalized. On the same day, the patient was examined in the dermatology department, where it was confirmed that the lesions were compatible with PPD and topical corticoid was prescribed. The patient was evaluated 15 days later but the lesions remained the same. At this point, an extensive review of the medical literature was carried out and one article [4] was found that described SD caused by amlodipine administration, indicating that the patient should stop taking the drug, which she did. The patient's lesions had improved 1 week later and disappeared after 1 month (Fig. 2). At 6-month follow-up, the patient was still not taking amlodipine and remained without skin lesions.

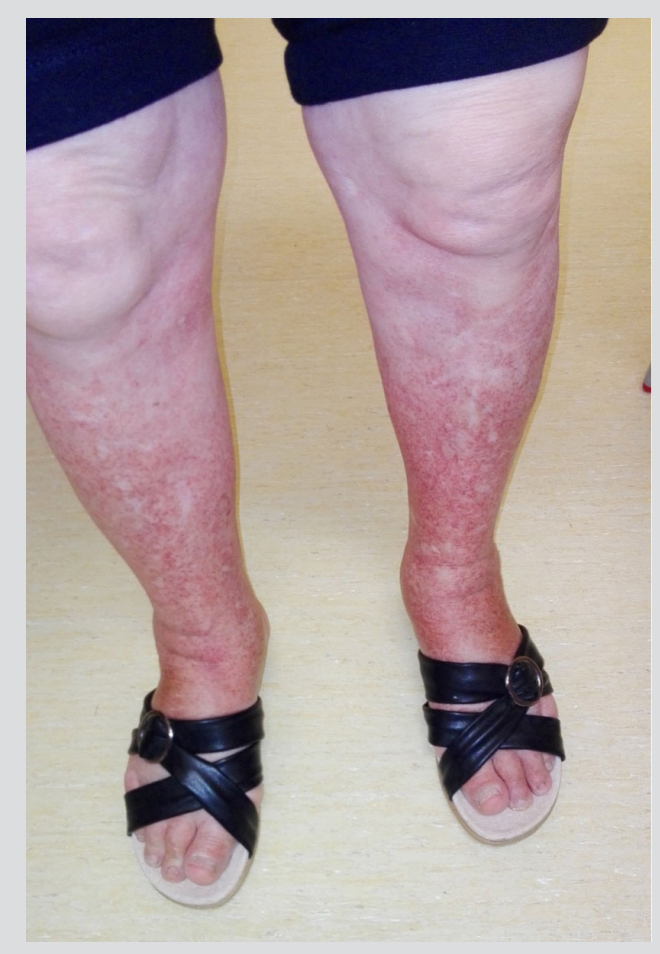

Figure 1. Skin lesions compatible with Schamberg's disease

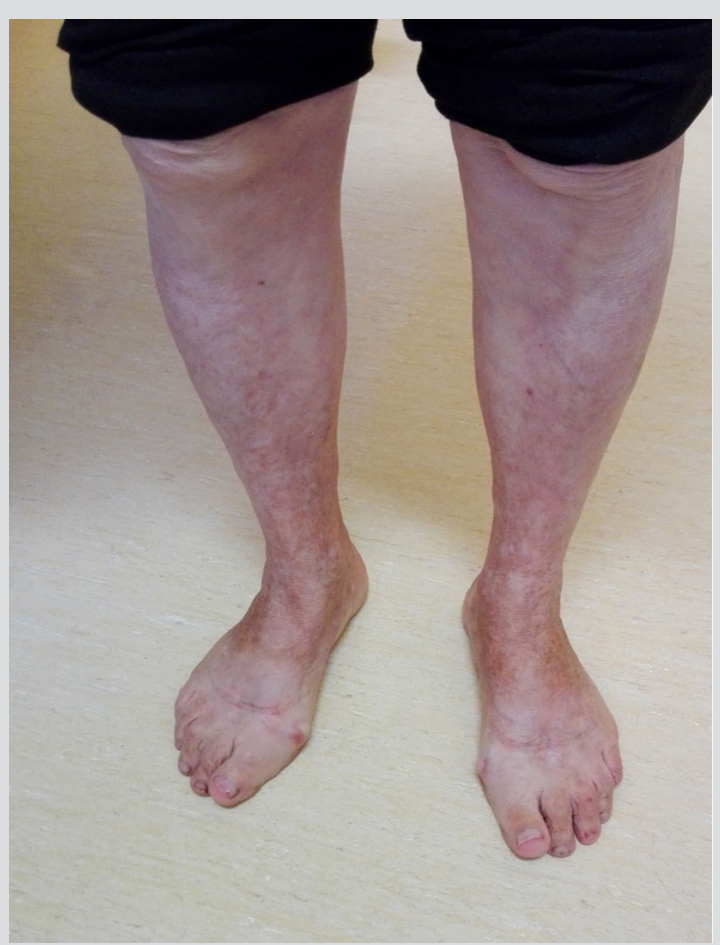

Figure 2. Skin lesions after cessation of amlodipine

\section{DISCUSSION}

SD was first described in 1901 by Jay Frank Schamber ${ }^{[5]}$. it is one of the five recognized clinical patterns of PPD which present a similar histopathology: SD, purpura annularis telangiectodes, lichen aureus, pigmented purpuric lichenoid dermatosis and eczematid-like purpura of Doucas and Kapetanakis ${ }^{[1]}$.

PPD is more frequent in men and can occur at any age. SD is mostly asymptomatic except for slight pruritus that can occasionally occur, and characteristically, the lesions present as pinhead-sized reddish puncta that further form irregular plaques of orange or brown pigmentation. There are three different hypotheses regarding the pathogenesis of PPD: capillary fragility, humoral immunity and cellular immunity ${ }^{[2]}$.

In most cases of PPD the aetiology is unknown ${ }^{[1,2,6]}$. However, several important cofactors influence disease presentation: venous hypertension ${ }^{[7]}$, exercise ${ }^{[2]}$ and gravitational dependency ${ }^{[7,8]}$, capillary fragility ${ }^{[2]}$, focal infections ${ }^{[9]}$ and chemical ingestion ${ }^{[8]}$.

The literature reports that drugs are the most frequent causative factor in PPD, especially in SD ${ }^{[1]}$. The drugs that cause PPD are acetaminophen, aspirin, adalin, carbromal, chlordiazepoxide, glipizide, glybuzole, hydralazine, meprobamate, persantin, reserpine, thiamine, interferon-alfa and medroxyprogesterone acetate injection ${ }^{[1]}$. The authors found one article ${ }^{[4]}$ in the literature that associated SD with the administration of amlodipine.

As there are no medical interventions of proven benefit for this skin condition ${ }^{[1]}$, symptomatic treatment is recommended through the use of topical corticosteroids and histamines for the pruritus ${ }^{[2,7,9]}$. Other treatments such as psoralen photochemotherapy ${ }^{[10]}$, griseofulvin ${ }^{[11]}$, 
pentoxifylline ${ }^{[12,13]}$, cyclosporine ${ }^{[14]}$, rutoside and ascorbic acid ${ }^{[6,15]}$ have been suggested.

According to the literature, SD is characterized by the skin alteration described above and by a normal haematological profile and coagulation tests, conditions that were observed in our patient.

Taking into account the clinical presentation, the resolution of the skin condition with the suspension of amlodipine and the fact that correct treatment had been administered without effect, in our opinion the skin alteration in this case was associated with amlodipine administration. Moreover, other authors have reported one case where SD was associated with the administration of amlodipine ${ }^{[4]}$.

In conclusion, further investigation should be considered to develop a better understanding of the possible correlation between amlodipine, a drug used daily, and PPD. In the meantime, bearing in mind that there are two cases describing an association between SD and amlodipine, we recommend early amlodipine discontinuation in patients who present with PPD in order to prevent progression of the skin lesions. Moreover, exhaustive and careful evaluation of the characteristics of the medications that each patient takes chronically is important, especially patients in polypharmacy, as such analysis may not only prevent these situations but also allow their early resolution.

This article is equally intended to draw physicians' attention to the importance of recognizing this disease because patients are frequently disturbed by its appearance. Physicians who are unaware of these findings will subject the patient to multiple, extensive and unnecessary examinations to exclude an underlying disease such as vasculitis, coagulopathy or associated haematological malignancy.

\section{REFERENCES}

1. Sardana K, Sarkar R, Sehgal VN. Pigmented purpuric dermatoses: an overview. Int J Dermatol 2004;43:482-488.

2. Tristani-Firouzi P, Meadows KP, Vanderhooft S. Pigmented purpuric eruptions of childhood: a series of cases and review of literature. Pediatr Dermatol 2001;18:299-304.

3. Torrelo A, Requena C, Mediero IG, Zambrano A. Schamberg's purpura in children: a review of 13 cases. J Am Acad Dermatol 2003;48:31-33.

4. Schetz D, Kocic I. A new adverse drug reaction - Schamberg's disease caused by amlodipine administration - a case report. Br J Clin Pharmacol 2015;80:1477-1478.

5. Schamberg J. Report of three cases of progressive pigmentary dermatoses with particular reference to the blood cholesterol. Br J Dermatol 1927;39:389-393.

6. Schober SM, Peitsch WK, Bonsmann G, Metze D, Thomas K, Goerge T, Luger TA, Schneider SW. Early treatment with rutoside and ascorbic acid is highly effective for progressive pigmented purpuric dermatosis. J Dtsch Dermatol Ges 2014;12:1112-1119.

7. Newton RC, Raimer SS. Pigmented purpuric eruptions. Dermatol Clin 1985;3:165-169.

8. Dowd PM, Champion RH. Purpura. In: Champion RH, Burton JL, Burns DA, Breathnach SM, editors. Textbook of dermatology, 6th edn. Vol. 3. Oxford: Blackwell Scientific Publications; 1998; pp. 2141-2154.

9. Taketuchi Y, Chinen T, Ichikawa Y, et al. Two cases of unilateral pigmented purpuric dermatosis. J Dermatol 2001;28:493-498.

10. Wong WK, Ratnam KV. A report of two cases of pigmented purpuric dermatoses treated with PUVA therapy. Acta Derm Venereol 1991;71: 68- 70.

11. Tamaki K, Yasaka N, Osada A, et al. Successful treatment of pigmented purpuric dermatosis with griseofulvin. Br J Dermatol 1995;132:159-160.

12. Wahba-Yahav AV. Schamberg's purpura: association with persistent hepatitis B surface antigenemia and treatment with pentoxifylline. Cutis 1994;54:205-206.

13. Kano T, Hirayama K, Orihara M, Shiohara T. Successful treatment of Schamberg's disease with pentoxifylline. J Am Acad Dermatol 1997;36:827-830.

14. Okada K, Ishikawa O, Miyachi Y. Purpura pigmentosa chronica successfully treated with oral cyclosporin A [letter]. Br J Dermatol 1996;134:180-181.

15. Rheinhold U. Treatment of progressive pigmented purpura with oral bioflavanoids and ascorbic acid: an open pilot study in 3 patients. J Am Acad Dermatol 1999;41:20. 